\title{
El gobierno de la bancarrota. Racionalidad neoliberal y educación financiera en Portugal
}

\section{Fernando Ampudia de Haro}

Universidade Europeia. Laureate International Universities

Centro de Investigações e Estudos em Sociologia (CIES). Instituto Universitário de Lisboa (IUL)

fernando.ampudia@europeia.pt; fernando.haro@iscte.pt

Recibido: 07-05-2013

Aceptado: 21-02-2014

\section{Resumen}

El objetivo de este artículo es analizar los presupuestos fundamentales que informan la denominada educación financiera y, específicamente, la promoción de la misma a través del Plan Nacional de Formación Financiera (PNFF) aplicado en Portugal. Con arreglo al esquema teórico de los estudios neofoucaltianos sobre gubernamentalidad, se procede a realizar un estudio crítico del PNFF y de diferentes informes complementarios elaborados por el Banco de Portugal acerca de la pertinencia para el país de un programa de educación financiera. El análisis incide prioritariamente en el tipo de diagnóstico que se ofrece desde el PNFF sobre la situación de Portugal, la conceptualización de las deficiencias que es preciso subsanar en la relación de los portugueses con las finanzas personales, las prácticas que se sugieren para su corrección, el modelo de organización social que se propone y el arquetipo de ciudadano que se propugna.

Palabras clave: racionalidad política; neoliberalismo; gubernamentalidad; educación financiera; Portugal.

Abstract. The government of bankruptcy: Neoliberal rationality and financial education in Portugal

The aim of this paper is to analyze the core principles of financial education programmes and, more specifically, their promotion and diffusion in Portugal through the so-called National Financial Education Plan (PNFF). According to the theoretical approach defined by neo-Foucaltian studies on governmentality, the main dimensions of PNFF are examined in order to identify the plan's a) diagnosis of the financial situation in Portugal; b) its conceptualization of the moral and cognitive deficits of the Portuguese in the domain of financial issues; c) its proposal to solve these deficits; d) its model of society articulated by market mechanisms; and e) its ideal of financial citizen.

Keywords: political rationality; neoliberalism; governmentality; financial education; Portugal. 


\section{Sumario}

1. Financierización: el marco de los programas de educación financiera

2. ¿Por qué es necesaria la educación financiera? Deficiencias cognitivas y morales
3. La educación financiera de los portugueses como programa neoliberal

4. Conclusión

Referencias bibliográficas

El 11 de septiembre de 2012, el ministro de Hacienda portugués, Vítor Gaspar, convocaba a la prensa para informar sobre la quinta evaluación efectuada por la troika - formada por la Comisión Europea, el Banco Central Europeo y el Fondo Monetario Internacional - al plan de asistencia financiera al país. Su intervención se abría del siguiente modo: «El programa de ajuste económico de Portugal ha evitado la bancarrota del Estado portugués» (Correio da Manhã, 2011). Apenas unos días antes, el 26 de agosto, la Comisión Europea anunciaba un plan para familias endeudadas. Este era uno de los primeros puntos sobre los que había alertado la troika en un país en el que la deuda de los agregados familiares rondaba el 100\% del PIB y 700.000 de los mismos no alcanzaba a pagar sus créditos (Pereira y Gonçalves, 2011). Dos meses más tarde, Pedro Seixas Vale, presidente de la Asociación Portuguesa de Aseguradoras, sostenía que la cultura financiera debía aumentar en Portugal: «Hay personas con los mismos ingresos que los portugueses que ahorran más. Es una cuestión de educación y cultura financiera [...] Es preciso avanzar con un proceso pedagógico sobre la importancia del dinero» (Morato, 2011). He aquí tres noticias aptas para describir el trazo general de algunos de los discursos que pueblan la esfera pública portuguesa; discursos que dibujan un continuum argumental entre la insolvencia del Estado, la deuda de las familias y el déficit de conocimiento financiero de la población.

El propósito de este artículo es ocuparse, precisamente, de este último aspecto. Más específicamente, de la principal iniciativa desarrollada hasta hoy, a fin de corregir ese supuesto déficit: el Plan Nacional de Formación Financiera (PNFF). Como podrá comprobarse, ocuparse del PNFF llevará necesariamente a hablar de bancarrota individual y colectiva. No en vano, gran parte de la justificación aducida para su elaboración se basa en la consideración del mismo como herramienta adecuada para hacer frente a la problemática asociada a la deuda, ya sea pública o privada. Así pues, el objetivo de este trabajo es el escrutinio de los presupuestos fundamentales que informan el PNFF, asumiendo que éste es, simultáneamente, producto y vehículo transmisor de una racionalidad política neoliberal, entendida ésta en el sentido neofoucaltiano de los governmentality studies. Con arreglo al esquema teórico de la gubernamentalidad, se procede a realizar un estudio crítico del PNFF y de diferentes informes complementarios elaborados por el Banco de Portugal acerca de la pertinencia para el país de un programa de educación financiera. El análisis incide, prioritariamente, en el tipo de diagnóstico que se ofrece desde el PNFF sobre la situación de Portugal, la conceptualización de las deficiencias que es 
preciso subsanar en la relación de los portugueses con sus finanzas personales y las prácticas que se proponen para su corrección.

De acuerdo con esto, la primera sección del artículo aborda el tema de la financierización como marco general en el que se inscriben las iniciativas de educación financiera; un marco en el que destaca la pujanza de instituciones, mercados y actores financieros como protagonistas de la economía mundial. La segunda sección se abre con una introducción al discurso social del que se infiere la necesidad de educar financieramente a la ciudadanía, un discurso apuntado en los medios de comunicación que incide en las fallas cognitivas y morales de la población como explicación al problema del endeudamiento y de las dificultades financieras. Este tipo de discurso va a servir como introducción al análisis propiamente dicho del PNFF, que reelabora principalmente el argumento de las deficiencias cognitivas - pero no sólo- para construir su propia autolegitimación. Mediante este análisis, se trata de mostrar que la educación financiera es un dispositivo de gubernamentalidad que ambiciona la construcción de nuevos mecanismos de mercado, así como la configuración de un ciudadano esencialmente definido en clave financiera.

\section{Financierización: el marco de los programas de educación financiera}

El término financierización es relativamente reciente. Pese a todo, existe cierto consenso en torno al mismo que la literatura especializada se encarga de señalar:

a) De forma genérica, el concepto alude al predominio del capital que circula por el circuito financiero sobre aquel que se concentra en el terreno de la economía productiva. Ello sería el resultado de un proceso histórico que corresponde al paso de un sistema productivo-fordista a otro posfordistafinanciero (Epstein, 2005; Heilbron, 2005).

b) Este predominio supone una transformación del equilibrio entre los mercados financieros y las corporaciones empresariales e industriales en favor de los primeros. Dicha transformación lleva aparejada una constante presión de los dividendos sobre la política industrial y comercial a largo plazo (Langley, 2007).

c) A escala global, la economía aparece dirigida por las finanzas, que encuentran un soporte estructural y logístico en las tecnologías de la información y en el proceso de globalización económica (Martínez González-Tablas, 2012; Santos Ruesga, 2012).

d) El capitalismo financierizado presenta un conjunto relativamente homogéneo de manifestaciones y consecuencias. Entre las más visibles, destacan el aumento de la complejidad del mercado de divisas, la privatización de los servicios públicos, la independencia de los bancos centrales, la extensión del crédito en sus más diversas modalidades y la utilización del empleo como variable de ajuste y competitividad (Medialdea García y Sanabria Martín, 2013).

Resulta habitual que la caracterización del concepto sea efectuada en clave macrosociológica como un proceso objetivo de naturaleza económica, con 
capacidad de imposición sobre la conducta y la subjetividad individuales. Sin embargo, el proceso de financierización también posee su propia traducción en el ámbito de la cotidianeidad y la experiencia inmediata de la vida personal. El concepto «democratización de las finanzas» expresa esta presencia de lo financiero en el día a día. En su acepción descriptiva, se refiere, por un lado, a la ampliación de la participación en los mercados financieros de titulares de ingresos medios y bajos. Por otro lado, designa el conjunto de incentivos conducentes a la adquisición de productos financieros con el fin de satisfacer necesidades tales como la vivienda, la salud, la educación o la jubilación (Erturk et al., 2007). En su acepción normativa, es visto como el resultado deseable de una sociedad progresivamente orientada hacia el mercado como vía preferente de acceso a bienes y servicios, amén de instrumento generador de un orden social en el que prevalezca el principio de la libre elección individual (Shiller, 2007).

Es en este interregno entre la extensión de los mercados financieros y la deseabilidad de articular la provisión de bienes y servicios esenciales a través de los mismos, donde puede situarse de forma genérica la educación financiera (Bay et al., 2014). En líneas generales, esta tiene como misión proporcionar conocimiento sobre conceptos, productos y servicios de índole financiera. Pretende el desarrollo de capacidades en este terreno, así como el aumento de la confianza en relación con las finanzas individuales, sin dejar de llamar la atención sobre las diferentes oportunidades de inversión, ahorro y consumo y sus consiguientes riesgos. No deja de ser una definición bastante genérica que cabría complementar con las especificidades propias de los diferentes programas de formación financiera existentes. Con todo, resulta válida en la medida en que es transversal a esos programas, los cuales contemplan este denominador común.

Sin duda alguna, la OCDE es el organismo internacional que mayor protagonismo ha cobrado en el ámbito de la promoción de principios e iniciativas que den forma a programas de educación financiera (OECD, 2005a; 2005b; 2009a; 2009b). Del mismo modo, países como Estados Unidos, Reino Unido, Nueva Zelanda o Australia son los que poseen más experiencia en la materia. La Unión Europea no ha querido quedarse atrás y también ha dado su aval a la puesta en marcha de planes de educación financiera a través del Reglamento 1093/2010 del Parlamento Europeo y del Consejo (Santos y Costa, 2013: 757). Si nos referimos, por ejemplo, al caso español, el Plan Nacional de Educación Financiera ha conocido ya una primera fase (2008-2012) y se encuentra, a día de hoy, en la segunda, que se cerrará en 2017. El Banco de España y la Comisión Nacional del Mercado de Valores promovieron el primer programa piloto de formación financiera en el sistema educativo, el cual tuvo lugar durante el curso 2010-2011, contando con la participación de 3.000 alumnos de $3 .^{\circ}$ de ESO. Por su parte, Portugal ha elaborado su PNFF para el periodo 2011-2015 a partir del diagnóstico previo que supuso la encuesta de conocimiento financiero de 2010 (Banco de Portugal, 2010) y una primera iniciativa de 2008, la creación del Portal del Cliente Bancario. 
Estas páginas se ocupan de la educación financiera en su vertiente de discurso y conjunto de prácticas estructuradas de acuerdo con un tipo determinado de racionalidad política. No forma parte de su cometido un análisis comparado de programas, una evaluación de su impacto o una exploración de las principales dificultades que plantea cualquier decisión financiera y los potenciales obstáculos que limitan su efectividad ${ }^{1}$. De igual modo, es conveniente señalar que la actividad reguladora de un banco central como el portugués no se limita, como es obvio, a la elaboración de programas de educación financiera. La educación financiera forma parte de su labor de «supervisión comportamental», centrada en las relaciones que se establecen entre las instituciones financieras y sus clientes. La llamada «supervisión prudencial» se ocuparía de garantizar la estabilidad del sistema financiero, así como la seguridad de los depósitos que son confiados a las instituciones que lo componen. Que este artículo se ocupe prioritariamente de la educación financiera supone no poder atender a este segundo tipo de supervisión. En otras palabras, fijar la atención en la educación financiera no debe hacer creer al lector que esa es la única regulación prevista por el Banco de Portugal sobre el sistema financiero. Una vez hechas estas salvedades y delimitado el alcance de mi propuesta, es momento de adentrarse en el caso portugués.

\section{2. ¿Por qué es necesaria la educación financiera? Deficiencias cognitivas y morales}

Antes de entrar en el análisis propiamente dicho del PNFF portugués, conviene fijar algunos de los argumentos que, estando presentes en la esfera pública y en los medios de comunicación, contribuyen a fijar el sentido de la cuestión que se pretende definir, a saber: el endeudamiento, las causas del mismo y la necesidad de educar financieramente a los ciudadanos. Resulta útil observar como varios de estos argumentos serán reelaborados por el PNFF en el apartado en el que expresamente se justifica su propia idoneidad. Sin ánimo de exhaustividad y mediante una pequeña cala en la prensa escrita, puede identificarse como punto de partida el establecimiento de un «nosotros» colectivo responsable de la situación de Portugal. Más allá de la crisis financiera internacional, de los problemas estructurales de la economía o de las decisiones desacertadas de los gobernantes, Álvaro Santos Pereira, ministro de Economía entre 2011 y 2013, afirma que la culpa de esa situación es «[...] de todos nosotros (familias, empresas y Estado) [...] por habernos dejado endeudar muy por encima de lo que era aconsejable. O sea, la culpa de esta situación es de todos» (Pereira, 2011). Una formulación análoga la encontramos en las palabras del presidente de la República, Aníbal Cavaco Silva, cuando aseguraba, en primera persona del plural, «no podemos continuar viviendo por encima de nuestras posibilidades» (Jornal de Notícias, 2011). El problema estriba en una población que,

1. Para una aproximación a tales cuestiones, véanse los muy recomendables artículos de Santos y Costa (2013) y Santos (2013), junto a la bibliografía que ambos trabajos incluyen. 
según Vítor Bento, consejero de Estado, habría adoptado «una forma de vida de cigarra, de poco trabajo y mucho consumo", cuando lo que se requería con la entrada en la moneda única era una "vida de hormiga" (Jornal de Notícias, 2011). En el mismo sentido, Rui Leão Martinho, presidente del Colegio de Economistas, denuncia la connivencia de los portugueses con este tipo de comportamiento, al haber aceptado vivir en una «sociedad basada en los principios de poca riqueza creada y mucha financiación ajena» (Expresso, 2011).

Una vez asentada la cuestión del endeudamiento, producido por el acceso al crédito, hay que preguntarse por las razones que condujeron a ese estado financiero crítico. Dichas razones apuntan sistemáticamente a las deficiencias morales y cognitivas de los portugueses en tanto factores que explicarían un comportamiento financiero que urge ser corregido. Las deficiencias cognitivas se refieren a la falta de conocimiento, lagunas en la comprensión o ignorancia total sobre cuestiones de cariz financiero. Las deficiencias morales se centran en algún tipo de desorden en la satisfacción de los deseos o en la incapacidad para postergar su cumplimiento. En suma, desconocimiento e irresponsabilidad emergen como razones, las más de las ocasiones, entremezcladas en el discurso.

Son esclarecedoras, por ejemplo, las declaraciones de João Salgueiro, presidente de la Asociación Portuguesa de Bancos, al apuntar que los portugueses viven en una cultura del «apáñate como puedas» propia de "quien no hace cuentas». Esta falta de planificación y previsión es también «una cuestión de mentalidad estimulada por las campañas de publicidad» que alimentan el descontrol consumista de la población; un consumismo que se cifra en la adquisición de bienes superfluos: «Ha habido mucha gente que se ha endeudado para comprar ropa de marca, para vacaciones o para cambiar de coche; no sólo ha sido para comprar casa» (Correio da Manhã, 2008). El consumo se asimila a una suerte de desequilibrio o falta de autocontrol al que habría sucumbido un elevado número de personas. Valentim Xavier Pintado, profesor de economía de la Universidad Católica Portuguesa, explota argumentalmente esta veta al asegurar que «[...] un número significativo de portugueses, obcecados por el consumo, vive en una situación de sobreendeudamiento a lo largo de toda la vida». La deuda posee un componente compulsivo o patológico: «En las últimas dos décadas, el consumismo se ha convertido en una enfermedad en Portugal y ha provocado un endeudamiento récord de nuestras familias» (Pintado, 2008).

Si en estas últimas palabras la irresponsabilidad sobreviene a resultas de fallos en la capacidad de autorregulación, de acuerdo con otras opiniones, la misma procede de un cierto grado de analfabetismo financiero entre la población. Desde el Centro de Apoyo al Endeudado, una organización que ofrece servicios técnicos y legales para la reestructuración de deudas, se dice lo siguiente: «Los portugueses, por norma, son buenos pagadores». Mas lo que no hacen son «cuentas, ni las llamadas cuentas de la compra. Y, muchas veces, tienen deudas mensuales superiores a sus ingresos». Así, "las familias portuguesas dejaron de hacer ese ejercicio y vivían en una opulencia artificial [...] muchas se endeudaron por cosas irrelevantes, como un viaje o tarjetas para comprar ropa» 
(Faria, 2012). En consonancia con estas fallas, Natália Nunes, del Gabinete de Apoyo al Sobreendeudado de la Asociación de Defensa del Consumidor (DECO), afirma: «[En tiempos de crisis] las personas deben aprender a conocer el valor del dinero [...] La mayoría no sabe cómo gasta el dinero. Dicho de otra forma, no sabe cuánto cuesta efectivamente cada producto o servicio que se compra y se sorprende cuando suma todos sus gastos» (Neves, 2008).

La conjunción de deficiencias morales y cognitivas alumbra un argumentario en el que el endeudamiento y la bancarrota familiar sobrevienen a consecuencia de excesos y fiebres consumistas, ignorancia, irresponsabilidad, incapacidad para postergar la satisfacción de deseos o mala gestión del dinero. En todo caso, como problema, tiende a individualizarse asumiendo que sus causas radican en algún tipo de fallo en lo tocante a la capacidad de autorregularse (Walker, 2012a). El encuadramiento social del endeudamiento difumina y elimina de la ecuación la producción social de las condiciones que lo hacen posible, las cuales remiten a cuestiones como el desempleo, la precarización de las relaciones laborales, la transferencia del riesgo desde el Estado hasta los agentes individuales en áreas como las pensiones o la salud, los incentivos fiscales como sustitutos de políticas públicas de vivienda o la desregulación financiera (Brasset y Clarke, 2012) ${ }^{2}$. Si el planteamiento de la cuestión del endeudamiento y la bancarrota se asienta en pilares individualizados, su solución también presentará un carácter individual: la alfabetización financiera como acción educativa sobre y con los portugueses se entiende que proporcionará la base para su autocapacitación técnico-moral. Se expresa la necesidad de desarrollar programas de reajuste individual de una conducta financiera tenida como problemática y especialmente peligrosa para la colectividad (Lessenich, 2011). Peligrosa en la medida en que la agregación de comportamientos financieros imprudentes o ignorantes sitúa a la sociedad en una situación de riesgo nacional; hace de Portugal un país «hipotecado».

\section{La educación financiera de los portugueses como programa neoliberal}

El PNFF y, en general, todas las disposiciones que complementan esta tentativa de educar financieramente a la población responden a una modalidad de racionalidad política neoliberal. Avanzando argumentos que serán discutidos más adelante, es posible afirmar que la educación financiera se concibe como un mecanismo mediante el cual encauzar u orientar el comportamiento individual —asumido como comportamiento autónomo - en aras de la explotación financiera de nuevos nichos de consumidores o de la teórica mejora del funcionamiento de productos y servicios financieros. Retengamos, pues, la idea de encauzar u orientar, el supuesto de la autonomía individual y la noción de

2. La literatura especializada sobre la situación portuguesa es consensual en torno a esa disolución de la producción social del riesgo. Al respecto, véase Frade et al. (2008) y, desde una óptica crítica y desmitificadora, Santos (2011). Para una perspectiva internacional comparada, véase Niemi et al. (2009). 
mecanismo de creación y mejora de mercados, conceptos todos ellos cruciales dentro de ese tipo de racionalidad neoliberal.

El neoliberalismo no es aquí una ideología o una modalidad específica de políticas públicas más o menos orientadas al mercado (Larner, 2000). De acuerdo con una perspectiva foucaltiana y siguiendo los análisis de los teóricos de la gubernamentalidad ${ }^{3}$, se entiende por racionalidad política el haz de objetivos - políticos, sociales, económicos, pedagógicos, espirituales, militares... - perseguidos en el ejercicio del poder, así como los principios que respaldan la consecución de los mismos, principios - libertad, justicia, equidad, responsabilidad, prosperidad...- en nombre de los cuales se materializa dicho ejercicio. Cada variante de racionalidad política posee una concepción propia sobre la naturaleza de los individuos gobernados y, asimismo, articula objetivos, principios y dicha concepción según un vocabulario y un discurso particulares (Gordon, 1991; Rose y Miller, 1992: 178; De Marinis, 1999: 87-88). La racionalidad política neoliberal, en contraposición a la racionalidad política welfarista, apuesta por economizar, en la máxima medida de lo posible, el ejercicio del poder (Ampudia de Haro, 2006: 66-67). Enfatiza la necesidad de que sean los propios individuos quienes aseguren personalmente la provisión de bienes y servicios y que gestionen sus riesgos vitales —enfermedad, desempleo, inseguridad, incapacitación laboral, vejez...-, acudiendo para ello al mercado. El riesgo es concebido, ya como una oportunidad de crear riqueza e innovación, ya como el motor de la acción y la responsabilidad individuales frente a la incertidumbre (O’Malley, 1996: 204). Si de lo que se trata es de economizar en el ejercicio del poder, ello implica que los individuos, en tanto gobernados, habrán de contribuir con la máxima intensidad y competencia posibles a su autogobierno. Empero los individuos no son aquí cuerpos que disciplinar o resistencias que haya que doblegar (Vázquez García, 2005: 178-179), sino elementos sobre los que hay que actuar contando con su libertad: se gobierna sobre y con los gobernados empleando esa autonomía que se les atribuye para alinearla o reconducirla con arreglo a los objetivos de gobierno. Según esto, serán los portugueses quienes, autogobernando su conducta financiera, sienten las bases para solucionar el problema del endeudamiento y conjurar una parte importante de los problemas financieros del país.

La elaboración del PNFF corrió a cargo del Banco de Portugal, la Comisión del Mercado de Valores Mobiliarios y el Instituto de Seguros de Portugal, contando con el visto bueno expreso y la aprobación del ministro de Hacienda del momento, Vítor Gaspar. El documento se abre con una definición genérica del concepto de alfabetismo financiero, entendido como «capacidad para realizar juicios informados y tomar decisiones teniendo en vista la gestión del dinero» (CNSF, 2011: 5). La gestión del dinero incluye el análisis de cuestio-

3. Línea de análisis centrada en las nociones de gobierno y gubernamentalidad desarrolladas por Foucault como complemento y especificación de su noción de poder. Al respecto, contamos con útiles publicaciones introductorias, entre las que cabe señalar Burchell et al. (1991) o la didáctica presentación de De Marinis (1999). 
nes financieras ligadas al bienestar material de los ciudadanos, la planificación del futuro, la respuesta adecuada a situaciones diarias que afectan a las decisiones económicas, la comprensión de los principios y el funcionamiento de los mercados financieros o la aptitud para evaluar nuevos productos bancarios que satisfagan objetivos personales a corto, medio y largo plazo. Proporcionar instrucción financiera es el medio de alcanzar un objetivo último, no otro que la configuración de un mercado de productos y servicios financieros eficiente que, a la vez, contribuya positivamente al desarrollo y crecimiento de la economía nacional. Y, para eso, los agentes que actúan en ese mercado tendrán que conducirse a fin de colaborar al logro de esa eficiencia.

El PNFF parte de una constatación inicial: el aumento en la complejidad y la cantidad de los productos financieros que son comercializados. Este hecho dificulta su comprensión, su evaluación y, ante todo, el tomar una decisión cabalmente informada y ajustada a los deseos y a las pretensiones del consumidor. Al cabo, se reconoce que el origen y la propagación de la crisis se encuentra en el sistema de bancos comerciales y en una elevada concesión de crédito (CNSF, 2011: 6). Por lo tanto, lo que se pretende es realizar una intervención en el mercado capacitando a los consumidores, lo que redundaría en un mejor funcionamiento del mismo. Esa capacitación es el recurso principal para eliminar la asimetría informativa que hoy caracteriza a la relación entre el banco y sus clientes:

Esta mayor complejidad implica también que, sin una adecuada formación financiera, la asimetría de información existente entre las instituciones financieras y los consumidores sea cada vez más evidente, factor que, al reducir el poder negociador del consumidor, contribuye también a dificultar el proceso de decisión. (CNSF, 2011: 6)

Una información completa, clara y rigurosa acerca de productos y servicios junto a la capacidad de analizarla y evaluarla correctamente eliminaría esa asimetría. Y es que la misma no deja de ser un fallo del mercado que hay que enmendar. El Banco de Portugal, en su informe de supervisión de 2011, al hilo de la necesidad de elaborar programas de educación financiera, afirma lo siguiente:

En la medida en que decisiones informadas conducen a elecciones más eficientes, la disponibilidad de información permite corregir un importante fallo de mercado, justificando de esta forma la intervención del regulador. (Banco de Portugal, 2011: 55)

Se esboza con más claridad la pertinencia de la intervención externa al mercado, en este caso del Banco de Portugal, como entidad supervisora y reguladora; intervención sólo justificable si es para conseguir que el mercado, a partir de esa injerencia en su dinámica, funcione eficientemente. Como puede comprobarse, la asimetría informativa pertenece, sin género de dudas, a la categoría «imperfecciones del mercado» que han de ser corregidas (Banco de 
Portugal, 2011: 24). El efecto necesario de esta corrección es el surgimiento de un tipo de participante en el mercado que aumenta su margen de negociación con los bancos en virtud de su formación; un participante en condiciones de desvelar la opacidad que oculta el grado de riesgo asociado a productos y servicios bancarios: la asimetría devendría en simetría al conocerse con detalle lo que una de las partes vende y lo que la otra compra. Un individuo debidamente alfabetizado en términos financieros poseería la capacidad de monitorizar aquellos productos y servicios, lo que a su vez, redunda en la eficiencia del mercado. En este punto, la reposición de la simetría es declaradamente benéfica; algo que apunta la OCDE en su documentación sobre educación financiera; documentación que el Banco de Portugal sigue muy de cerca en su calidad de promotor y artífice del PNFF.

$\mathrm{La}$ OCDE sostiene que los consumidores financieramente educados son positivos para la economía. El razonamiento es el que sigue: un individuo con formación financiera demandará productos más ajustados a sus necesidades, lo que, a su vez, supondrá un incentivo para que las instituciones desarrollen nuevos productos. Así, aumentará la competencia, se estimulará la innovación y la calidad, será posible captar más ahorro, se canalizarán más recursos dirigidos a la inversión y crecerá la economía nacional (OECD, 2005a). Al mismo tiempo, el consumidor funciona como un supervisor con sus decisiones de compra, circunstancia que incluso permitiría una reducción de la "carga regulatoria" (regulatory burden) que pesa sobre las instituciones financieras (OCDE, 2005a: 13). Dicho de otro modo y esta vez en la versión del Banco de Portugal:

Aunque la educación financiera no debe sustituir a la necesidad de regulación de los mercados, puede ser eficiente en áreas donde la regulación, para producir efectos semejantes, podría implicar costes significativos sobre el normal funcionamiento de los mercados. (Banco de Portugal, 2010: 25)

Fijemos esta última expresión —normal funcionamiento de los mercados-, porque es justamente para eso para lo que se concibe el PNFF. La reducción de asimetrías informativas, la monitorización ejercida por el consumidor, el estímulo a la innovación y la competencia y la apuesta por la autorregulación frente a la intervención externa al mercado sentarín las bases de un sistema financiero más eficiente y estable, circunstancia que sólo puede beneficiar al ciudadano si, como se advierte repetidamente, tiene que recurrir al mercado para satisfacer ciertas necesidades vitales. Al respecto, el PNFF se manifiesta sin ambages: la crisis ha provocado «la reducción de los beneficios asociados a la seguridad social, lo que implica una mayor transferencia de riesgo y responsabilidad para los consumidores, especialmente en la formulación de planes de pensiones y salud» (CNSF, 2011: 6). Un individuo cognitivamente apto estará en condiciones de asumir esa transferencia desarrollando una autogestión financiera que le permita hacerse cargo de sí mismo. Si el sistema de seguridad social puede ser visto como un medio de socializar los riesgos vitales que, sin poder ser eliminados, sí es factible neutralizar (Ewald, 1996: 
390), su descapitalización, efecto de la crisis, requerirá una individualización del riesgo para el que se debe estar cognitivamente preparado. Transferir el riesgo al individuo es, también, hacer del ahorro el medio a través del cual éste ejercita su responsabilidad. La irresponsabilidad, al contrario, se conecta con el sobreendeudamiento, una condición que comporta "consecuencias económicas y sociales a nivel individual y colectivo" (CNSF, 2011: 12). Esto es, la irresponsabilidad en la contratación de créditos no sólo es lesiva para la persona o las familias, sino que también afecta a la sociedad en su conjunto. De ahí que se promueva «una utilización responsable del crédito ponderando adecuadamente su peso en el presupuesto familiar» (CNSF, 2011: 12), una responsabilidad de extrema relevancia, debido a "la gran diversidad de alternativas de acceso al crédito» y «la relativamente creciente facilidad en su obtención» (CNSF, 2011: 12). De nuevo, será la capacitación cognitiva del individuo la que le permitirá optar, de entre esta diversidad, por aquello que considere pertinente.

A su vez, la inevitabilidad de recurrir al mercado como abastecedor de bienes y servicios básicos otorga sentido al concepto de «inclusión financiera» definida como el «acceso a unos servicios bancarios mínimos que incluyan una cuenta corriente y servicios de pago esenciales» (CNSF, 2011: 11). Según la encuesta sobre conocimientos financieros de la población portuguesa (Banco de Portugal, 2010) — documento de diagnóstico que sirve como base para la confección del PNFF-, el $11 \%$ de la población con edad igual o superior a 16 años no es titular de ninguna cuenta bancaria y un 29\% de los que sí la tienen no posee ningún otro producto financiero. Mas, ¿por qué se considera deseable esa inclusión? Por dos motivos: porque «tener una cuenta bancaria es un requisito esencial para acceder a determinados bienes y servicios», además de constituir un «indicador de integración social» (Banco de Portugal, 2010: 6). En coherencia con el propósito de inclusión, el PNFF identifica cuatro sectores de la población sobre los que actuar preferentemente: estudiantes de enseñanza básica y secundaria, estudiantes universitarios, trabajadores por cuenta propia o ajena y los llamados «grupos vulnerables» (CNSF, 2011: 15), a saber: desempleados, inmigrantes, jubilados con bajos ingresos y jóvenes sin escolaridad básica obligatoria.

\subsection{Gubernamentalidad: el ciudadano financiero}

Hasta aquí, tenemos un arquetipo de individuo que autorregula su conducta financiera en virtud de su competencia y su responsabilidad y cuyas decisiones resultan indisociables de su participación en los mercados tal y como sugiere el concepto de inclusión financiera. El PNFF permite observar cómo la intervención sobre la conducta en el sentido de la autorregulación no es estrictamente disciplinaria o coactiva, sino que se cuenta con la propia iniciativa del individuo para el desarrollo de la práctica regulatoria. Ello nos pone sobre la pista del neoliberalismo como racionalidad política, un modo de comprenderlo que se aleja de concepciones excesivamente formalistas, estáticas y hasta coherentes del mismo. Tales concepciones ven en el neoliberalismo una doctrina político- 
económica, cuyo objetivo es la reducción de la intervención estatal hasta niveles mínimos, normalmente identificados con el simple mantenimiento de las condiciones que garanticen la libre competencia entre los agentes económicos y las funciones de defensa nacional y control del orden público. Al mismo tiempo que se limita la acción estatal, se liberarían las iniciativas individuales maniatadas por dicha acción. Sin embargo, esta visión del neoliberalismo no deja de ser reduccionista y simplificadora, si lo que queremos es entender las implicaciones del proceso abierto en Portugal en pos de la educación financiera de sus ciudadanos.

En este caso, la acción estatal, encarnada en el PNFF y sus productores promotores (el Banco de Portugal, la Comisión Nacional del Mercado de Bienes Mobiliarios y el Instituto de Seguros Portugués), se ocupa de la dinamización de un mercado que ya existe, el financiero, y de la creación de las condiciones que amplíen sus márgenes en coordinación con la autonomía individual de los sujetos gobernados. La inclusión financiera y la transferencia del riesgo caminan en esa dirección, apostando por una mayor integración de la población en el circuito financiero, a la vez que se sustituye la provisión pública de bienes y servicios por su adquisición vía mercado, adquisición mediada por la capacitación cognitiva que proporciona la educación financiera. La participación y la decisión financieras, responsables y competentes, redundarían en un beneficio colectivo: no poner a la sociedad en peligro de bancarrota e impulsar la generación de riqueza y desarrollo económico.

La educación financiera es, en definitiva, un dispositivo de gubernamentalidad, un modo de pensar el gobierno de las poblaciones y de ponerlo en práctica. Este gobierno es articulado mediante los principios del mercado como institución a través de la cual la sociedad satisface sus necesidades, a la vez que genera una mejora en las condiciones económicas de la colectividad. La dinámica del mercado está sometida a imperfecciones susceptibles de corrección para garantizar que exista un ajuste entre la oferta y la demanda sin necesidad de correcciones ulteriores. Una de esas imperfecciones es, en la línea del PNFF, la insuficiente capacitación cognitiva de los participantes en el mercado. La educación financiera tendrá como cometido enseñar a estos participantes a tomar decisiones óptimas, porque habrá aumentado su nivel de formación. En cierta medida, cada una de estas decisiones reflejará toda la información disponible para un bien o un servicio determinado por el que se acepta pagar un determinado precio. Nos hallamos frente a un modelo de ciudadano financiero (Pearson, 2009: 2-3) que conoce los riesgos del mercado, que participa activamente en la arena financiera y que depende de instrumentos financieros para garantizar su seguridad material. Por agregación, esta conducta financiera responsable y organizada deviene en un modo de coordinar socialmente las acciones de múltiples individuos, lo cual genera un resultado colectivo provechoso para todos. Mas, y es necesario insistir en este punto, estos individuos se conciben como sujetos autónomos; se asume esa autonomía como un dato a priori. Así, el objetivo será alinear tal autonomía con el objetivo de gobierno, esto es, la dinamización de un mercado que funcione y genere crecimiento 
económico. $\mathrm{O}$, en otras palabras, alinear el autogobierno individual con los propósitos generales de gobierno.

Llegamos, de esta forma, al último aspecto relevante: la cuestión del autogobierno. Hemos visto que es condición sine qua non para la configuración eficiente del mercado que tenga lugar un tipo de acción individual ajustada a lo que se espera de un ciudadano con formación financiera. Este ciudadano ejercita su responsabilidad decidiendo adecuadamente de acuerdo con sus intereses, sus necesidades y su conocimiento, además de sopesando los riesgos que comporta su decisión. La apuesta por el autogobierno muestra sin tapujos la transversalidad de la racionalidad política neoliberal, presente tanto en posiciones liberal-conservadoras como en propuestas socialdemócratas-progresistas. En las primeras, esa confianza en el autogobierno se reviste del vocabulario de la soberanía y de la suprema responsabilización individual frente a las injerencias de los poderes públicos. En las segundas, tal confianza adopta el ropaje del «empoderamiento" (empowerment) y de la dotación de medios para la construcción de un ciudadano independiente (Pathak, 2013). En cualquiera de los dos casos, resultaría apropiado plantearse cómo se concibe al individuo que se desvía en relación con una conducta financiera tenida como competente.

Lo cierto es que el énfasis en la agencia individual y la eliminación de los factores sociales que encuadran la cuestión del endeudamiento y del sobreendeudamiento crea las condiciones de posibilidad para moralizar o psicologizar ambas cuestiones. De este modo, se presentarán en clave de consumismo, derroche, deseo desenfocado, tentativa de falsear la posición social, compulsividad, ansiedad, incapacidad para aplazar la gratificación o baja autoestima combatida a base de compras sostenidas. (Sinclair, 2010; Alonso et al, 2011; Walker, 2012b). Pese a todo, esos factores sociales son fácilmente identificables. Así, las dificultades financieras se hallan estrechamente relacionadas con los cortes salariales de los funcionarios públicos, con el aumento de los impuestos sobre el consumo - especialmente el IVA-, con el aumento de las tasas de copago en la sanidad pública, con los recortes en las deducciones en el Impuesto sobre la Renta de las Personas Físicas (IRS en Portugal), con la reducción del periodo y del montante del subsidio de desempleo, por los cortes y la congelación de las pensiones o por el aumento continuado del paro (Santos y Costa, 2013: 758).

Por el contrario, el individuo que se desvía del patrón de responsabilidad financiera es, como vimos en el discurso social sobre el endeudamiento, el irresponsable, el dependiente o el incapaz. En definitiva, un estándar de persona cuya conducta tiene consecuencias lesivas para la comunidad. No en vano, su comportamiento incrementaría el nivel de endeudamiento general y perpetuaría una cultura de dependencia que obligaría a aumentar el gasto público en forma de subsidios y ayudas, al no hacerse cargo, por ejemplo, de su pensión o de sus gastos de salud. O, como apunta Walker (2012a), una suerte de delincuente cognitivo que revela su incapacidad para aprender contenidos básicos de finanzas personales, una incapacidad que se extiende a la aplicación de lo aprendido y, por extensión, al ejercicio del autogobierno. 


\section{Conclusión}

Una de las principales críticas a la que se enfrentan hoy los programas de educación financiera procede del campo de la economía del comportamiento, disciplina encargada del estudio de los factores psicológicos, emocionales y cognitivos que intervienen en las decisiones financieras (Santos, 2010). Al respecto, parece no existir evidencia empírica sólida que confirme que el aumento de información y de conocimiento financiero se traduzca en una mejora de las decisiones. En este sentido, el homo economicus que se guía en función de criterios de racionalidad instrumental y que decide óptimamente de acuerdo con las señales que emiten los precios en tanto agregadores de toda la información existente en el mercado, no pasaría de un constructo teórico. Ocurre que estas teóricas decisiones óptimas son sistemáticamente torpedeadas por atajos mentales, omisión o ignorancia intencionada de datos, errores sistemáticos o exceso de confianza.

Con todo, esta falta de consistencia y de eficacia no constituye ningún obstáculo para la puesta en marcha de los programas de educación financiera. El propio regulador y promotor del PNFF, el Banco de Portugal, justifica la pertinencia de educar financieramente a la población, pese a reconocer que todavía no se haya demostrado una correlación positiva entre educación financiera y decisiones óptimas:

Es importante señalar que estas dificultades no invalidan la contribución de la formación financiera a un mayor conocimiento y responsabilidad financiera; dificultades que resultan antes de las propias dificultades para analizar ese impacto [de la educación financiera sobre las decisiones] y de la necesidad de realizar investigaciones adicionales en el terreno de las finanzas personales. (Banco de Portugal, 2010: 21)

Lo único que prueba la ausencia de evidencias empíricas es la necesidad de realizar más investigaciones en esta área. En consecuencia, de esa ausencia no se puede concluir que no exista relación entre educación financiera y decisión y, en última instancia, no deslegitimaría una iniciativa como el PNFF.

Sin embargo, el análisis en términos de gubernamentalidad de tales iniciativas debe ir más allá de las limitaciones técnicas y prácticas de la educación financiera o de su repercusión sobre las decisiones de los consumidores. En términos de gubernamentalidad, lo que tenemos es un modo de pensar la organización económica de la sociedad y la conducta financiera, un modo de pensar con su correspondiente traducción práctica. El presupuesto principal que maneja la educación financiera es que la autocapacitación generará, como resultado agregado, una masa de ciudadanos financieramente responsables, cuya actuación dotaría al mercado de mayor estabilidad y de un sistema de autocorrección de sus desequilibrios propiciado por la vigilancia que ejercen los consumidores. Estos asumirían la transferencia de los riesgos otrora socializados en sistemas de provisión pública de bienes y servicios, y los gestionarían de acuerdo con la pericia técnica y el sentido de responsabilidad que 
proporcionaría la educación financiera. Así, la falta de esa pericia o los fallos que advienen de su ausencia se convierten en la antesala de una conducta que pone en peligro a la sociedad en su conjunto. No en vano, la irresponsabilidad financiera aparece indisociablemente ligada al riesgo de bancarrota, en el que incurriría el país al generalizarse conductas financieramente irresponsables. La racionalidad neoliberal, con su apuesta por la economización en el ejercicio del poder y la articulación entre los objetivos de gobierno y la acción autónoma de los individuos, emerge, en este punto, con rotunda claridad, enlazando con una construcción discursiva de la bancarrota a la que se le ha extirpado su componente social, sistémico y político. La moralización y tecnificación cognitiva de la cuestión de la bancarrota aboca a la configuración de un ciudadano que se hace responsable a través de sus elecciones en la arena de los mercados.

En consecuencia, el objeto de análisis de una sociología que se quiera pública y crítica habrá de centrarse en la repercusión y en las dimensiones sociales de la educación financiera. Aquí he apuntado varias: la negación del encuadramiento social de la conducta financiera y su consiguiente moralización y psicologización; el papel de la educación financiera como legitimadora de la desactivación del sistema público de bienestar; el papel que cumple la formación financiera en la dinamización y expansión de los mercados financieros, o la transformación del compromiso cívico y de la ciudadanía en mero autogobierno financiero.

\section{Referencias bibliográficas}

Alonso, Luis Enrique; Fernández Rodríguez, Carlos J. e Ibáñez Rojo, Rafael (2011). «Del consumismo a la culpabilidad: En torno a los efectos disciplinarios de la crisis económica». Política y Sociedad, 48 (2), 353-379.

Ampudia de Haro, Fernando (2006). «Administrar el yo: Literatura de autoayuda y gestión del comportamiento y los afectos». Revista Española de Investigaciones Sociológicas (REIS), 113, 49-75.

BANCo De PoRTUgal (2010). Inquérito à literacia financeira da população portuguesa [en línea]. Lisboa: Banco de Portugal. Departamento de Supervisão Bancária. $<$ http://clientebancario.bportugal.pt/ptPT/Publicacoes/InqueritoLiteraciaFinanceira/Biblioteca\%20de\%20Tumbnails/S\%C3\%ADntese\%20dos\%20resultados\%20 do\%20Inqu\%C3\%A9rito\%20\%C3\%A0\%20Literacia\%20Financeira.pdf> [Consulta: 15 febrero 2014].

- (2011). Relatório de Supervisão Comportamental 2010 [en línea]. Lisboa: Banco de Portugal.

$<$ http://clientebancario.bportugal.pt/ptPT/Publicacoes/RSC/Biblioteca\%20de $\% 20$ Tumbnails/Relat\%C3\%B3rio\%20Supervis\%C3\%A3o\%20Comportamental\%20 2010.pdf> [Consulta: 15 febrero 2014].

- (2012). Relatório de Supervisão Comportamental 2011 [en línea]. Lisboa: Banco de Portugal.

$<$ http://clientebancario.bportugal.pt/ptPT/Publicacoes/RSC/Biblioteca $\% 20 \mathrm{de} \% 20$ Tumbnails/Relat\%C3\%B3rio\%20de\%20Supervis\%C3\%A3o\%20Comportamental\%20(2011).pdf> [Consulta: 15 febrero 2014]. 
«Bastonário dos Economistas diz que portugueses são culpados da austeridade». Expresso, 20 de octubre de 2011.

Bay, Charlotte; Catasús, Bino y Johed, Gustav (2014). «Situating financial literacy». Critical Perspectives on Accounting [en línea], 25 (1), 36-45. <http://dx.doi.org/10.1016/j.cpa.2012.11.011>.

Brasset, James y Clarke, Chris (2012). «Performing the Sub-prime Crisis: Trauma and the Financial Event». International Political Sociology [en línea], 6 (1), 4-20. <http://dx.doi.org/10.1111/j.1749-5687.2012.00148.x>.

Burchell, Graham; Gordon, Colin y Miller, Peter (eds.) (1991). The Foucault Effect: Studies in Governmentality. Londres: Harvester Wheatsheaf.

CNSF (Conselho Nacional de Supervisores Financeiros) (2011). Plano Nacional de Formação Financeira (2011-2015) [en línea]. Lisboa: Banco de Portugal. Serviço de Edições e Publicações.

<http://www.cmvm.pt/CMVM/Coopera\%C3\%A7\%C3\%A3o\%20Nacional/ Conselho\%20Nacional\%20de\%20Supervisores\%20Financeiros/Documents/ Plano\%20Nacional\%20de\%20Forma\%C3\%A7\%C3\%A3o\%20Financeira.pdf> [Consulta: 15 febrero 2014].

"Economista justifica a crise por portugueses terem feito "vida de cigarra"». Jornal de Notícias, 26 de mayo de 2011.

Epstein, Gerald A. (ed.) (2005). Financialization and the World Economy. Cheltenham, Camberley, Northampton MA: Edward Elgar Publishing.

Erturk, Ismail; Leaver, Adam; Froud, Julie; Williams, Karel e Johal, Sukhdev (2007). "The democratization of finance?: Promises, outcomes and conditions». Review of International Political Economy [en línea], 14 (4), 553-575. <http://dx.doi.org/10.1080/09692290701475312>.

«Estamos a salvar o país da bancarrota». Correio da Manhã, 11 de septiembre de 2011.

Ewald, François (1996). «Philosophie de la précaution». L'Année Sociologique, 46 (2), 348-412.

FAria, Isabel (2012). «Soluções para endividados» Correio da Manhã, 20 de junio.

Frade, Catarina; Lopes, Claúdia; Jesus, Fernanda y Ferreira, Teresa (2008). Um perfil dos sobreendividados em Portugal: Relatório Final. Centro de Estudos Sociais (CES). Faculdade de Economia. Universidade de Coimbra.

Gordon, Colin (1991). "Governmental Rationality». En: Burchell, Graham; GorDon, Colin y Miller, Peter (eds.) (1991). The Foucault Effect: Studies in Governmentality. Londres: Harvester Wheatsheaf.

Heilbron, Johan (2005). «Taking a stock: Toward a historical sociology of financial regimes». Economic Sociology: The European Electronic Newsletter [en línea], 7 (1), 3-17.

<http://econsoc.mpifg.de/archive/esoct05.pdf> [Consulta: 15 febrero 2014].

Langley, Paul (2007). «Uncertain subjects of Anglo-American Financialization». Cultural Critique [en línea], 65, 67-91. <http://dx.doi.org/10.1353/cul.2007.0009>.

LARner, Wendy (2000). «Neo-Liberalism: Policy, Ideology, Governmentality». Studies in Political Economy, 63, 5-25.

Lessenich, Stephan (2011). «Constructing the Socialized Self: Mobilization and Control in the Active Society». En: Brockling, Ulrich; Krasmann, Susanne y Lenke, Thomas (eds.). Governmentality: Current Issues and Future Challenges. Nueva York, Londres: Routledge. 
Marinis, Pablo de (1999). "Gobierno, gubernamentalidad, Foucault y los anglofoucaltianos (O un ensayo sobre la racionalidad política del neoliberalismo)». En: Ramos, Ramón y García Selgas, Fernando (eds.). Globalización, riesgo, reflexividad: Tres temas de la teoría social contemporánea. Madrid: CIS.

Martínez González-Tablas, Ângel (2012). «Financiarización, economía y sociedad». En: Alonso, Luis Enrique y Fernández Rodríguez, Carlos J. (eds.). La financiarización de las relaciones salariales: Una perspectiva internacional. Madrid: Los Libros de la Catarata.

Medialdea García, Bibiana (2012). «La financiarización de la economía mundial: Hacia una caracterización». Revista de Economía Mundial, 32, 195-227.

Medialdea García, Bibiana y Sanabria Martín, Antonio (2013). «La financiarización de la economía mundial: hacia una caracterización». Revista de Economía Mundial, 33, 195-227.

Morato, Paula (2011). "Presidente da APS: Cultura financeira tem que crescer em Portugal». Diário de Notícias, 31 de octubre.

«Não podemos continuar a viver acima das nossas possibilidades». Jornal de Notícias, 16 de mayo de 2011.

Neves, Céu (2008). "O consumidor precisa aprender a conhecer o valor do dinheiro». Diário de Notícias, 11 de enero.

Niemi, Johanna; Ramsay, Iain y Whitford, William C. (eds.) (2009). Consumer Credit, Debt and Bankruptcy: Comparative and International Perspective. Oxford y Portland (OR): Hart Publishing.

OECD (Organisation for Economic Co-operation and Development) (2005a). Improving Financial Literacy: Analysis of Issues and Policies. París: OECD Publishing.

- (2005b). Recommendation on Principles and Good Practices for Financial Education and Awareness: Recommendation of the Council. París: OECD Publishing.

- (2009a). OECD Project on Financial Education. París: OECD Publishing.

- (2009b). Financial Literacy and Consumer Protection: Overlooked aspects of the Crisis. OECD Recommendation on Good Practices on Financial Education on Awareness Relating to Credit. París: OECD Publishing.

O’Malley, Pat (1996). "Risk and Responsibility». En: Barry, Andrew; Osborne, Thomas y Rose, Nikolas (eds.). Foucault and Political Reason: Liberalism, neo-liberalism and rationalities of government. Londres: UCL Press.

Pathak, Pathik (2013). «Ethopolitics and the Financial Citizen». The Sociological Review [en línea]. <http://dx.doi.org/10.1111/1467-954X.12119>.

Pearson, Gail (2009). Financial Services and Compliance in Australia. Cambridge University Press.

Pereira, Álvaro Santos (2011). «Quem tem a culpa?». Notícias Sábado, enero.

Pereira, Helena y GonçAlves, Luís (2011). «Bruxelas lança plano para famílias endividadas». Sol, 26 de agosto.

Pintado, Valentim Xavier (2008). "Consumismo e endividamento». Expresso, 17 de marzo.

«Portugueses culpados por endividamento». Correio da Manhã, 25 de septiembre de 2008.

Rose, Nikolas y Miller, Peter (1992). «Political Power beyond the State: problematics of government». The British Journal of Sociology [en línea], 43 (2), 173-205. <http://dx.doi.org/10.1111/j.1468-4446.2009.01247.x>. 
Ruesga, Santos M. (2012). «La financiarización de las relaciones laborales». En: AlonSo, Luis Enrique y Fernández Rodríguez, Carlos J. (eds.). La financiarización de las relaciones salariales: Una perspectiva internacional. Madrid: Los Libros de la Catarata.

Santos, Ana Cordeiro (2010). The Social Epistemology of Experimental Economics. Londres y Nueva York: Routledge.

- (2011). «Temos vivido acima das nossas possibilidades?». Le Monde Diplomatique - Edicão Portuguesa, serie II, 57.

- (2013). «Financial literacy, financialisation and neo-liberalism». FESSUD Working Paper Series [en línea], 11.

$<$ http://fessud.eu/wp-content/uploads/2013/04/Financial-Literacy-Financialisation-and-Neo-liberalism-FESSUD-Working-Paper-11.pdf> [Consulta: 17 febrero 2014].

SAntos, Ana Cordeiro y Costa, Vânia (2013). «Regular o consumidor?: Novas tendências de política no setor financeiro». Análise Social, 209, XLVIII (4.º), 756-791.

Shiller, Robert J. (2007). «Risk Management for Households: The Democratization of Finance». Conferencia en Sixth Annual Bank for International Settlements Conference "Financial System and Macroeconomic Resilience» [en línea]. Brunnen, Suiza, 18-19 de junio.

<https://www.bis.org/events/brunnen07/shillerpap.pdf> [Consulta: 15 febrero $2014]$.

Sinclair, Timothy J. (2010). «Round up the Usual Suspects: Blame and the Subprime Crisis». New Political Economy [en línea], 15 (1), 91-107. <http://dx.doi.org/10.1080/13563460903553657>.

VÁzQuez García, Francisco (2005). Tras la autoestima: Variaciones sobre el yo expresivo en la modernidad tardía. San Sebastián: Tercera Prensa.

WaLker, Carl (2012a). «Cognitive delinquency and Techniques of Governmentality: Neoliberal Constructions of Financial Inadequacy in the UK». Journal of Community \& Applied Social Pschycology [en línea], 22 (6), 533-538. $<$ http://dx.doi.org/10.1002/casp.1127>.

- (2012b). «Neoliberal Ideology and Personal Debt in the United Kingdom». En: Walker, Carl; Johnson, Katherine y Cunningham, Liz (eds.). Community Psychology and the Socioeconomics of Mental Distress. International Perspectives. Palgrave: MacMillan. 